\title{
PENGEMBANGAN STRATEGI MANAJEMEN PENGETAHUAN UNTUK MENDUKUNG PELAKSANAAN REFORMASI BIROKRASI: SEBUAH STUDI KASUS DI KEMENTERIAN PERINDUSTRIAN
}

\author{
Nurzaitun Purwasih ${ }^{1}$ and Dana Indra Sensuse ${ }^{2}$ \\ ${ }^{1}$ Balai Besar Tekstil Kementerian Perindustrian R.I Jln. Jend. Ahmad Yani No. 390 Bandung 40272 \\ ${ }^{2}$ Fakultas Ilmu Komputer Universitas Indonesia Kampus UI Depok 16424 \\ E-mail: zaitun@kemenperin.go.id and dana@cs.ui.ac.id
}

\begin{abstract}
Bureaucratic reform program is a bureaucratic change efforts towards the expected profile. One of program bureaucratic reform support is a knowledge management. Ministry of Industry (Ministry of Industry) as a driver and builder of national industry needs to change and improve bureaucracy so as to improve the ability of the industry sector in the face of global competition. Along with its efforts to implement bureaucratic reform, the Ministry of Industry has the implementation of knowledge management initiatives, but does not yet have a comprehensive knowledge management strategy. Ministry of Industry focus is on improving the quality of public services, one of which is supported by the development of e-government. $\neg$ the development process of e-government involves a variety of knowledge are scattered in various locations, both inside and outside the organization. This study seeks to formulate the knowledge management strategy with a focus on the development of e-government targets in order to reform the bureaucracy. The formulation of the strategy is done by using a knowledge strategy framework Zack. Strategies are formulated as follows: Ministry of Industry need to document work experiences into written form; Kemenperin need to increase the awareness of employees to share knowledge; Ministry of Industry needs to improve coordination and cooperation within the framework of knowledge management, both internal and inter-working unit with external parties; Ministry of Industry needs to facilitate storage and distribution of IT-based knowledge that can be reached easily by all employees of the Ministry of Industry; and the Ministry of Industry should establish management commitment to support the implementation of knowledge management.
\end{abstract}

Keywords: knowledge management strategy, bureaucratic reform, e-government, knowledge strategy framework Zack

\begin{abstract}
Abstrak
Program reformasi birokrasi merupakan sebuah upaya perubahan menuju profil birokrasi yang diharapkan. Salah satu program pendukung reformasi birokrasi adalah manajemen pengetahuan. Kementerian Perindustrian (Kemenperin) sebagai penggerak dan pembina industri nasional perlu melakukan perubahan dan perbaikan birokrasi sehingga dapat meningkatkan kemampuan sektor industri dalam menghadapi persaingan global. Seiring dengan upayanya melaksanakan reformasi birokrasi, Kemenperin memiliki inisiatif pelaksanaan manajemen pengetahuan, namun belum memiliki strategi manajemen pengetahuan yang komprehensif. Fokus Kemenperin ada pada peningkatan kualitas pelayanan publik yang salah satunya didukung oleh pembangunan e-government. Proses pengembangan e-government melibatkan berbagai pengetahuan yang tersebar di berbagai lokasi, baik di dalam maupun di luar organisasi. Penelitian ini berusaha merumuskan strategi manajemen pengetahuan dengan fokus pada target pengembangan e-government dalam rangka reformasi birokrasi. Perumusan strategi dilakukan dengan menggunakan kerangka kerja strategi pengetahuan Zack. Strategi yang dirumuskan antara lain: Kemenperin perlu melakukan dokumentasi pengalaman-pengalaman kerja ke dalam bentuk tertulis; Kemenperin perlu meningkatkan kesadaran pegawai untuk berbagi pengetahuan; Kemenperin perlu meningkatkan koordinasi dan kerjasama dalam rangka pengelolaan pengetahuan, baik antar unit kerja internal maupun dengan pihak eksternal; Kemenperin perlu memfasilitasi media penyimpanan dan pembagian pengetahuan berbasis TI yang dapat dijangkau dengan mudah oleh seluruh pegawai Kemenperin; dan Kemenperin perlu membangun komitmen manajemen dalam mendukung pelaksanaan manajemen pengetahuan.
\end{abstract}

Kata Kunci : strategi manajemen pengetahuan, reformasi birokrasi, e-government, kerangka kerja strategi pengetahuan Zack 


\section{Pendahuluan}

Reformasi birokrasi merupakan program utama yang dilakukan pemerintah dalam rangka mewujudkan prinsip clean government dan good governance. Penyempurnaan kebijakan nasional di bidang aparatur akan mendorong terciptanya kelembagaan yang sesuai dengan pelaksanaan tugas pokok dan fungsi (tupoksi) masing-masing Kementerian/Lembaga (K/L) dan Pemerintah Daerah (Pemda), manajemen pemerintahan dan manajemen sumber daya manusia (SDM) aparatur yang efektif, serta sistem pengawasan dan akuntabilitas yang mampu mewujudkan pemerintahan yang berintegritas tinggi. Implementasi hal-hal tersebut akan mendorong perubahan mindset dan culture set setiap birokrat ke arah budaya yang lebih profesional, produktif, dan akuntabel.

Gambar 1 mendeskripsikan pola pikir pencapaian visi reformasi birokrasi, sebagaimana tertuang dalam Peraturan Presiden Republik Indonesia nomor 81 tahun 2010 tentang Grand
Design Reformasi Birokrasi 2010-2015. Pada bagan tersebut dapat dilihat bahwa pelaksanaan reformasi birokrasi didukung oleh beberapa hal, salah satunya adalah program quick wins. Quick wins merupakan suatu langkah inisiatif yang mudah dan cepat dicapai dalam mengawali suatu program yang besar dan sulit, demi mendapatkan momentum awal yang positif dan meningkatkan kepercayaan instansi untuk melakukan suatu perubahan yang berat. Selanjutnya, pelaksanaan reformasi birokrasi disertai monitoring dan evaluasi yang dilakukan secara periodik dan melembaga untuk mencegah terjadinya penyimpangan dan melakukan koreksi. Selain itu, reformasi birokrasi juga perlu didukung oleh penerapan manajemen perubahan, manajemen pengetahuan, dan penegakan hukum. Dengan adanya manajemen pengetahuan sebagai pendukung dalam pelaksanaan reformasi birokrasi diharapkan dapat terjadi suatu proses pembelajaran dan tukar pengalaman yang efektif bagi setiap K/L dan Pemda.

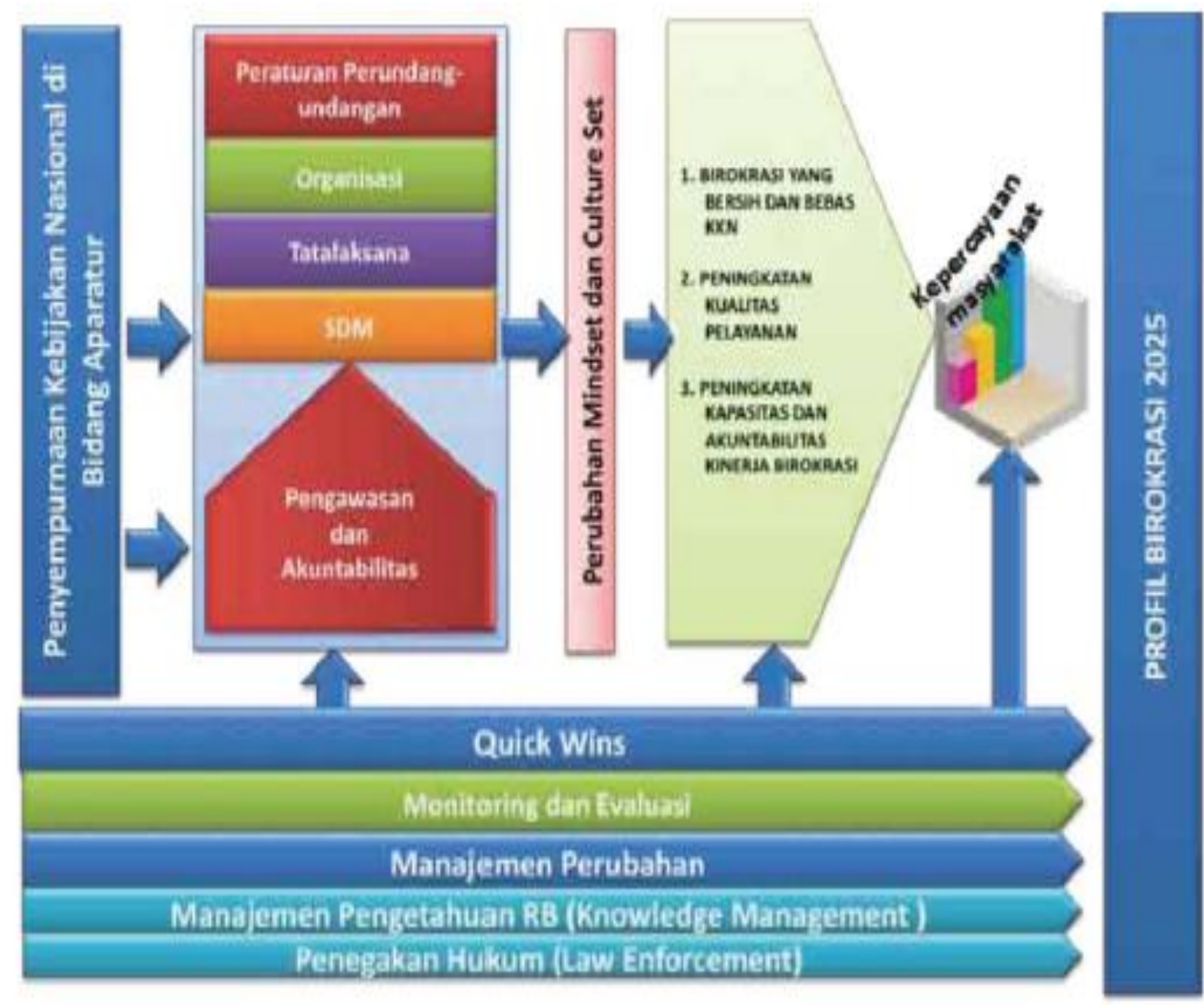

Gambar 1. Pola Pikir Pencapaian Visi Reformasi Birokrasi (Peraturan Presiden no. 81 tahun 2010) 
Pemerintahan, Kementerian Perindustrian (Kemenperin) mempunyai tugas untuk menyelenggarakan urusan di bidang perindustrian. Sebagai penggerak dan pembina industri nasional, Kemenperin perlu melakukan suatu perubahan dan perbaikan birokrasi sehingga dapat meningkatkan kemampuan sektor industri dalam menghadapi persaingan global. Kemenperin menetapkan peningkatan kualitas pelayanan publik sebagai quick wins, yang didukung oleh peningkatan kualitas SDM dan pengembangan $e$ government.

Sebagai bagian dari rencana aksi reformasi birokrasi, Kemenperin memiliki inisiatif pelaksanaan manajemen pengetahuan, namun belum dapat terlaksana. Setelah dilakukan penggalian masalah, ditemukan beberapa hal yang menjadi penyebab belum terlaksananya inisiatif tersebut. Dari aspek SDM diketahui bahwa pegawai belum menyadari pentingnya manajemen pengetahuan bagi organisasi dan bagi pelaksanaan tugasnya. Hal ini disebabkan oleh belum dipahaminya konsep manajemen pengetahuan. Dari aspek kebijakan, belum terdapat kebijakan mengenai penerapan manajemen pengetahuan di Kemenperin sebagai dasar hukum pelaksanaan manajemen pengetahuan. Dari aspek manajemen pengetahuan diketahui bahwa belum ada strategi manajemen pengetahuan sebagai acuan proses pengelolaan manajemen pengetahuan.

Penelitian ini berusaha menyelesaikan salah satu akar masalah yaitu belum adanya strategi manajemen pengetahuan sebagai acuan proses pengelolaan pengetahuan. Berdasarkan hal tersebut, maka tujuan penelitian ini adalah merumuskan strategi manajemen pengetahuan yang dapat mendukung pelaksanaan reformasi birokrasi Kemenperin.

Penelitian ini dibatasi pada hal-hal sebagai berikut:

1. Melakukan perumusan strategi manajemen pengetahuan yang mampu mendukung pelaksanaan reformasi birokrasi Kemenperin.

2. Strategi manajemen pengetahuan fokus pada domain pengembangan e-government dalam reformasi birokrasi. Hal ini dikarenakan pengembangan $e$-government adalah salah satu upaya peningkatan pelayanan publik sebagai quick wins reformasi birokrasi Kemenperin serta mendukung seluruh area perubahan dalam reformasi birokrasi.

3. Implementasi sistem manajemen pengetahuan tidak termasuk ke dalam ruang lingkup penelitian ini.

Penelitian ini diharapkan dapat memberikan manfaat bagi organisasi maupun bagi dunia akademik. Manfaat bagi organisasi adalah diharapkan dukungan strategi manajemen pengetahuan yang dihasilkan oleh penelitian ini mampu mendukung pelaksanaan reformasi birokrasi di Kemenperin, khususnya dalam penyelenggaraan pengembangan e-government. Sedangkan bagi dunia akademik adalah diharapkan penelitian ini dapat memberi masukan mengenai bentuk strategi manajemen pengetahuan untuk mendukung reformasi birokrasi di Indonesia.

\section{Data, Informasi, dan Pengetahuan}

Menurut Davenport dan Prusak (1998), data adalah seperangkat fakta objektif dan diskrit mengenai sebuah hal; meliputi fakta, observasi, dan persepsi yang merepresentasikan angka-angka mentah atau pernyataan-pernyataan yang mungkin tidak memiliki konteks, makna, atau tujuan.

Informasi adalah data yang memiliki makna; memiliki relevansi dan tujuan (Davenport dan Prusak, 1998). Fakta-fakta dapat berupa data atau informasi, tergantung pada individu yang memanfaatkan fakta tersebut (Becerra dan Sabherwal, 2010). Sebuah fakta dapat merepresentasikan informasi bagi seseorang, sementara bagi orang lain fakta tesebut hanyalah data. Hal tersebut dipengaruhi oleh peran relatif setiap individu terhadap fakta.

Davenport dan Prusak (1998) menyatakan bahwa pengetahuan adalah paduan mengalir dari pengalaman yang terbingkai, nilai, informasi yang memiliki konteks, dan pemahaman ahli yang menyediakan kerangka kerja untuk menilai dan memadukan pengalaman-pengalaman serta informasi baru. Becerra dan Sabherwal (2010) mendefinisikan pengetahuan sebagai keyakinan yang sudah dibuktikan kebenarannya mengenai hubungan di antara konsep-konsep yang relevan terhadap bidang tertentu. Pengetahuan adalah informasi yang memungkinkan aksi dan keputusan; informasi yang memiliki tujuan.

Pada sebuah organisasi, pengetahuan seringkali melekat pada dokumen-dokumen, repositori, rutinitas, proses, praktik dan norma organisasi. Pengetahuan dapat tersimpan di dalam individu, artefak, atau entitas organisasi (1).

$$
\text { Becerra dan Sabherwal (2010) }
$$

mengklasifikasikan pengetahuan sebagai berikut:

1. Pengetahuan deklaratif dan pengetahuan prosedural. Pengetahuan deklaratif atau pengetahuan substantif fokus pada keyakinan mengenai hubungan di antara variabel. Sedangkan pengetahuan prosedural fokus pada keyakinan terhadap rangkaian langkah-langkah yang saling berhubungan atau aksi-aksi untuk mewujudkan tujuan.

2. Pengetahuan tacit dan pengetahuan eksplisit. Pengetahuan tacit terletak di dalam benak 
individu pemiliknya, memiliki sifat sulit diekspresikan dan diformalkan. Pengetahuan semacam ini melibatkan pemikiran, intuisi, dan dugaan. Sifat dari pengetahuan tacit adalah personal dan berdasarkan pengalaman individu. Sedangkan pengetahuan eksplisit adalah pengetahuan yang telah diekspresikan ke dalam bentuk kata-kata dan angka-angka. Pengetahuan semacam ini dapat dibagikan secara formal dan sistematis, baik dalam bentuk data, spesifikasi, acuan manual, dan sebagainya.

\subsection{Manajemen Pengetahuan}

Becerra dan Sabherwal (2010) mendefinisikan manajemen pengetahuan sebagai aktivitas-aktivitas dalam menemukan pengetahuan (knowledge discovery), membekukan pengetahuan (knowledge capture), membagikan pengetahuan (knowledge sharing), dan mengaplikasikan pengetahuan (knowledge application) dalam rangka meningkatkan dampak pengetahuan terhadap pencapaian tujuan organisasi dengan memanfaatkan biaya secara efektif.

Dalam Peraturan Menteri Pendayagunaan Aparatur Negara dan Reformasi Birokrasi (MenPANRB) nomor 14 tahun 2011, manajemen pengetahuan diartikan sebagai upaya terstruktur dan sistematis dalam mengembangkan dan menggunakan pengetahuan yang dimiliki untuk membantu proses pengambilan keputusan bagi peningkatan kinerja organisasi (Kementerian PANRB, 2011).

\subsection{Strategi Manajemen Pengetahuan}

Strategi manajemen pengetahuan adalah strategi yang membimbing dan mendefinisikan proses dan infrastruktur untuk mengelola pengetahuan (9). Strategi manajemen pengetahuan meliputi komponen umum dan komponen spesifik terkait karakteristik organisasi. Komponen umum antara lain: penekanan pengetahuan tacit atau eksplisit, eksplorasi atau eksploitasi pengetahuan, mekanisme pertukaran pengetahuan bersifat organisasi atau teknis. Sedangkan komponen spesifik tergantung kepada jenis organisasi dan pengetahuan yang dikelola. Strategi manajemen pengetahuan diperlukan sebuah organisasi untuk mengelola kesenjangan pengetahuan (knowledge gaps).

Zack (1999) menawarkan sebuah kerangka kerja yang disebut kerangka kerja strategi pengetahuan (knowledge strategy framework). Kerangka kerja tersebut diawali dengan strategi bisnis organisasi dan kaitannya dengan pengetahuan sebelum memulai program manajemen pengetahuan. Dengan demikian, strategi organisasi akan menuntun pengelolaan sumber daya dan kemampuan intelektual organisasi (Zack, 1999).

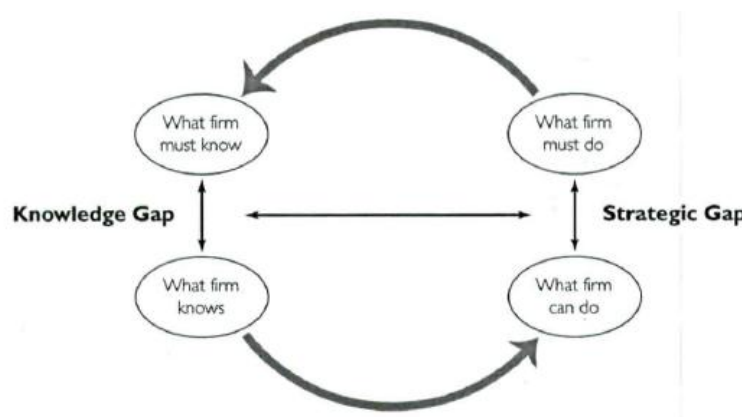

Gambar 2 Kerangka Kerja Strategi pengetahuan Zack (1999)

Gambar 2 menunjukkan penyelarasan antara kesenjangan strategis dengan kesenjangan pengetahuan di dalam sebuah organisasi. Menurut Zack (1999), kesenjangan pengetahuan secara langsung diturunkan dari dan diselaraskan dengan kesenjangan strategis. Strategi manajemen pengetahuan merupakan langkah-langkah yang diambil untuk menutupi kesenjangan tersebut.

\subsection{Penelitian Terkait}

Sebagai acuan penelitian, ditinjau 3 buah penelitian terkait strategi manajemen pengetahuan dan penggunaan kerangka kerja strategi pengetahuan Zack. Penelitian pertama adalah penelitian Matturro dan Silva (2005) yang menggunakan kerangka kerja Zack untuk menilai kesenjangan pengetahuan dalam organisasi pengembang perangkat lunak yang akan melakukan transisi dari pendekatan tradisional pengembangan perangkat lunak ke pendekatan software product line (SPL). Menurut Matturro dan Silva (2005), adopsi SPL melibatkan perubahan yang berimbas pada timbulnya kesenjangan pengetahuan antara ketersediaan pengetahuan organisasi saat ini dengan kebutuhan pengetahuan organisasi di masa yang akan datang. Identifikasi dan penilaian kesenjangan pengetahuan dilakukan agar organisasi dapat mengambil aksi untuk memperoleh atau mengembangkan pengetahuan yang dibutuhkan.

Penelitian kedua adalah penelitian Rolano (2008) yang bertujuan untuk membentuk strategi manajemen pengetahuan untuk mendukung koordinasi penanganan bencana sesuai model koordinasi United Nations Office for Coordinating Humanitarian Affairs (UN OCHA). Rolano menggunakan kombinasi kerangka Zack dan soft system methodology (SSM) untuk proses pembentukan strategi manajemen pengetahuan. Rolano menggunakan kerangka dari Zack (1999) untuk melakukan analisis terkait pengetahuan, 
aliran pengetahuan, serta kesenjangannya.

Penelitian ketiga adalah penelitian Iskandar (2009) yang melakukan pembentukan strategi manajemen pengetahuan sebagai bagian dari perancangan sistem manajemen pengetahuan (knowledge management system). Iskandar (2009) terlebih dahulu melakukan analisis keterkaitan strategi bisnis dan pengetahuan, kemudian melakukan pemetaan pengetahuan internal dan eksternal organisasi. Setelah itu dilakukan analisis kesenjangan strategis dan kesenjangan pengetahuan, kemudian merumuskan strategi manajemen pengetahuan untuk menutupi kesenjangan tersebut.

\section{Metode Penelitian}

Penelitian yang dilakukan adalah penelitian kualitatif dengan tujuan merumuskan strategi manajemen pengetahuan. Penelitian berupa studi kasus di salah satu lembaga pemerintahan, yaitu Kementerian Perindustrian. Perumusan strategi manajemen pengetahuan dilakukan dengan menggunakan kerangka kerja strategi pengetahuan Zack, dengan tahapan sebagai berikut:

1. Analisis kesenjangan strategis

Tahap pertama adalah dengan mengidentifikasi target dan realisasi rencana aksi pengembangan e-government dalam rangka reformasi birokrasi. Jika ditemui ketidaksesuaian antara realisasi dan target yang telah ditentukan, maka dilakukan identifikasi kendala yang menjadi penyebab ketidaksesuaian tersebut. Kemudian berdasarkan analisis terhadap kesenjangan dan penyebabnya, dirumuskan upaya-upaya yang diperlukan untuk menutupi kesenjangan strategis tersebut.

2. Analisis kesenjangan pengetahuan

Tahap selanjutnya identifikasi kebutuhan pengetahuan berdasarkan hasil wawancara terhadap tim reformasi birokrasi Kemenperin, serta diturunkan dari rencana aksi pengembangan e-government. Pengetahuan kemudian dikategorisasikan berdasarkan sumber pengetahuan, tipe pengetahuan, dan bentuk pengetahuan. Langkah selanjutnya adalah melakukan analisis kesenjangan pengetahuan berdasarkan kondisi pengetahuan yang diharapkan dan kondisi pengetahuan saat ini. Setelah kesenjangan pengetahuan teridentifikasi, ditentukan upaya-upaya yang diperlukan untuk menutupi kesenjangan pengetahuan, yang akan dirumuskan menjadi strategi manajemen pengetahuan.
Metode pengumpulan data dilakukan melalui wawancara dengan pihak yang terlibat langsung dalam kegiatan pengembangan e-government dalam mendukung program reformasi birokrasi Kemenperin. Selain itu, dilakukan juga analisis terhadap dokumen-dokumen pendukung lain yang berkaitan dengan reformasi birokrasi Kemenperin.

Metode analisis data yang dilakukan adalah analisis kualitatif desktriptif, yaitu dengan menginterpretasikan secara langsung hasil wawancara dan melakukan analisis terhadap dokumen pendukung.

\subsection{Perumusan Strategi Manajemen Pengetahuan}

Bagian ini menjelaskan analisis yang dilakukan untuk dapat merumuskan strategi manajemen pengetahuan yang dapat mendukung reformasi birokrasi Kemenperin, khususnya dalam pengembangan $e$-government.

Kemenperin menetapkan rencana aksi pengembangan e-government reformasi birokrasi dan menetapkan target untuk masing-masing rencana aksi. Analisis kesenjangan strategis dilakukan dengan membandingkan antara target dan realisasi rencana aksi pengembangan $e$ government. Jika terdapat ketidaksesuaian, maka dilakukan identifikasi kendala atau penyebab terjadinya ketidaksesuaian sebagai dasar penentuan upaya untuk menutupi kesenjangan strategis. Tabel 1 merupakan upaya untuk menutupi kesenjangan strategis yang teridentifikasi.

Identifikasi kebutuhan pengetahuan dalam rangka pengembangan e-government reformasi birokrasi Kemenperin dilakukan dengan menurunkannya dari rencana aksi pengembangan e-government dan analisis kesenjangan strategis. Selain itu, ada juga kebutuhan pengetahuan yang berdasar pada hasil wawancara dengan tim reformasi birokrasi Kemenperin. Pada Tabel 2 dapat dilihat pengetahuan yang dibutuhkan dalam rangka pengembangan e-government reformasi birokrasi Kemenperin.

Setelah dilakukan kategorisasi pengetahuan, diidentifikasi kondisi yang diharapkan terhadap pengetahuan-pengetahuan tersebut serta bagaimana kondisi saat ini. Setelah diidentifikasi kondisi pengetahuan, dilakukan analisis kesenjangan pengetahuan yang akan menghasilkan upaya-upaya yang diperlukan untuk menutupi kesenjangan tersebut. Berdasarkan kesenjangan yang ada perlu diidentifikasi upaya-upaya yang perlu dilakukan untuk menutupi kesenjangan tersebut yang direpresentasikan dalam bentuk proses manajemen pengetahuan. 
TABEL 1

HASIL ANALISIS KESENJANGAN STRATEGI

\begin{tabular}{|c|c|}
\hline $\begin{array}{l}\text { Rencana Aksi } \\
\text { Pengembangan } \\
\text { e-Government } \\
\end{array}$ & Upaya \\
\hline $\begin{array}{l}\text { Perluasan sistem } \\
e \text {-licensing }\end{array}$ & $\begin{array}{l}\text { a. Mendorong unit kerja teknis untuk proaktif memberikan informasi } \\
\text { jenis rekomendasi baru kepada Pusdatin. } \\
\text { b. Menugaskan pegawai yang khusus menangani proses perizinan. } \\
\text { c. Memberikan enforcement dari sisi kebijakan atau fitur aplikasi agar } \\
\text { pemroses perizinan pada unit kerja teknis melakukan barcode scan } \\
\text { formulir perizinan. }\end{array}$ \\
\hline $\begin{array}{l}\text { Pertukaran data } \\
\text { rekomendasi } \\
\text { dengan lembaga } \\
\text { lain }\end{array}$ & $\begin{array}{l}\text { a. Melakukan koordinasi dengan INSW terkait kebutuhan data } \\
\text { Kemenperin dan menentukan mekanisme pertukaran data. } \\
\text { b. Melakukan koordinasi dengan Kemendag terkait pertukaran data } \\
\text { bilateral. }\end{array}$ \\
\hline $\begin{array}{l}\text { Dukungan } \\
\text { terhadap } \\
\text { pengembangan } \\
\text { Jaringan } \\
\text { Dokumentasi dan } \\
\text { Informasi Hukum } \\
\text { (JDIH) online }\end{array}$ & $\begin{array}{l}\text { Melakukan sosialisasi dan enforcement kepada unit-unit kerja untuk } \\
\text { mengumpulkan peraturan-peraturan internalnya kepada Biro Hukum dan } \\
\text { Organisasi. }\end{array}$ \\
\hline $\begin{array}{l}\text { Pelayanan } \\
\text { terhadap } \\
\text { pertanyaan } \\
\text { masyarakat. }\end{array}$ & - \\
\hline $\begin{array}{l}\text { Publikasi } \\
\text { informasi publik } \\
\text { di website } \\
\text { Kemenperin }\end{array}$ & - \\
\hline
\end{tabular}

Pengembangan sistem informasi akademik a. Menuntaskan pelaksanaan pilot project.

b. Melakukan sosialisasi kepada sekolah-sekolah lain terkait penyeragaman sistem informasi akademik.
Pembangunan data warehouse industri a. Menentukan data-data yang akan dimasukkan ke dalam data warehouse.

b. Menentukan konsep data warehouse sesuai cakupan yang dibutuhkan.

Rekrutmen

CPNS online

\author{
Pengembangan \\ aplikasi \\ penerbitan \\ sertifikat \\ Tingkat \\ Komponen \\ Dalam Negeri
}

(TKDN) 
TABEL 2

IDENTIFIKASI KEBUTUHAN PENGETAHUAN

\begin{tabular}{|c|c|c|c|}
\hline Kebutuhan Pengetahuan & $\begin{array}{c}\text { Sumber } \\
\text { Pengetahuan } \\
\text { (Internal/ } \\
\text { Eksternal) }\end{array}$ & $\begin{array}{c}\text { Tipe } \\
\text { Pengetahuan } \\
\text { (Prosedural/ } \\
\text { Deklaratif) }\end{array}$ & $\begin{array}{l}\text { Bentuk } \\
\text { (Tacit/ } \\
\text { Eksplisit) }\end{array}$ \\
\hline Pengetahuan bidang teknologi informasi & $\begin{array}{l}\text { Internal dan } \\
\text { eksternal }\end{array}$ & Prosedural & $\begin{array}{l}\text { Tacit dan } \\
\text { eksplisit }\end{array}$ \\
\hline $\begin{array}{l}\text { Pengetahuan mengenai proses bisnis internal maupun yang } \\
\text { berhubungan dengan eksternal organisasi }\end{array}$ & $\begin{array}{l}\text { Internal dan } \\
\text { eksternal }\end{array}$ & Prosedural & $\begin{array}{l}\text { Tacit dan } \\
\text { eksplisit }\end{array}$ \\
\hline $\begin{array}{l}\text { Pengetahuan mengenai manfaat/outcomes dan harapan } \\
\text { pengguna dari sistem informasi (SI) }\end{array}$ & Internal & Deklaratif & $\begin{array}{l}\text { Tacit dan } \\
\text { eksplisit }\end{array}$ \\
\hline $\begin{array}{l}\text { Pengetahuan mengenai utilitas sistem informasi dan umpan } \\
\text { balik pengguna }\end{array}$ & $\begin{array}{l}\text { Internal dan } \\
\text { eksternal }\end{array}$ & Deklaratif & $\begin{array}{l}\text { Tacit dan } \\
\text { eksplisit }\end{array}$ \\
\hline Pengetahuan mengenai regulasi yang berlaku & $\begin{array}{c}\text { Internal dan } \\
\text { eksternal }\end{array}$ & Prosedural & $\begin{array}{l}\text { Tacit dan } \\
\text { eksplisit }\end{array}$ \\
\hline Pengetahuan mengenai reformasi birokrasi & $\begin{array}{l}\text { Internal dan } \\
\text { eksternal }\end{array}$ & Prosedural & $\begin{array}{l}\text { Tacit dan } \\
\text { eksplisit }\end{array}$ \\
\hline $\begin{array}{l}\text { Pengetahuan mengenai stakeholders perindustrian, kebutuhan } \\
\text { data/informasinya, serta ketersediaan data/informasi di } \\
\text { Kemenperin }\end{array}$ & $\begin{array}{l}\text { Internal dan } \\
\text { eksternal }\end{array}$ & Deklaratif & $\begin{array}{l}\text { Tacit dan } \\
\text { eksplisit }\end{array}$ \\
\hline
\end{tabular}

\section{Hasil Penelitian}

Hasil penelitian terdiri dari rumusan strategi manajemen pengetahuan dan dukungan infrastruktur manajemen pengetahuan yang dibutuhkan.

\subsection{Rumusan Strategi Manajemen Pengetahuan}

Berdasarkan analisis yang telah dilakukan, maka proses yang perlu dilakukan oleh Kemenperin terkait pengelolaan pengetahuan antara lain: Mendokumentasikan pengalamanpengalaman kerja ke dalam bentuk tertulis, meningkatkan kemauan pegawai untuk mempelajari pengetahuan-pengetahuan terkait TI untuk mendukung kegiatan pengembangan $e$ government, meningkatkan kesadaran pegawai untuk mau berbagi pengetahuan, meningkatkan kesadaran pegawai mengenai peran pengetahuan dan pemanfaatan kembali pengetahuan (knowledge reuse) dalam menunjang kegiatan organisasi, koordinasi dengan pihak eksternal dan melakukan penggalian informasi untuk mengetahui mekanisme pertukaran data, pembagian pengetahuan terkait mekanisme pertukaran data dengan pihak eksternal kepada pihak-pihak yang terkait dengan pengembangan $e$ government, kerjasama dengan pihak internal maupun eksternal untuk pemanfaatan pengetahuan mengenai proses bisnis dalam kegiatan pengembangan e-government sehingga sistem informasi yang dihasilkan benar-benar dapat mendukung proses bisnis organisasi, pendokumentasian manfaat/outcomes yang diperoleh dari aplikasi-aplikasi yang telah berjalan maupun yang sedang direncanakan, pembagian pengetahuan mengenai manfaat/outcomes SI kepada pihak terkait, salah satunya melalui presentasi capaian rencana kerja reformasi birokrasi di hadapan tim reformasi birokrasi Kemenperin atau melalui Intranet Kemenperin, evaluasi bersama antara Pusdatin dan pengguna aplikasi untuk mengetahui utilitas sistem informasi dan memperoleh umpan balik, penyediaan pengetahuan dalam bentuk tertulis dan mudah diakses agar pegawai bisa melakukan pembelajaran dengan mudah, melakukan dokumentasi dan diseminasi pengetahuan terkait reformasi birokrasi agar dapat dimanfaatkan oleh seluruh pegawai Kemenperin, melakukan pembagian pengetahuan terkait stakeholders perindustrian, kebutuhan data dan informasinya, serta ketersediaan data dan informasi yang dimiliki Kemenperin kepada pihak yang terlibat dalam pelayanan informasi industri. 
TABEL 3

HASIL ANALISIS KESENJANGAN PENGETAHUAN

\begin{tabular}{|c|c|}
\hline $\begin{array}{l}\text { Kebutuhan } \\
\text { Pengetahuan }\end{array}$ & Upaya \\
\hline $\begin{array}{l}\text { Pengetahuan bidang } \\
\text { teknologi informasi }\end{array}$ & $\begin{array}{l}\text { a. Meningkatkan kesadaran pegawai untuk mendokumentasikan pengalaman- } \\
\text { pengalaman kerjanya ke dalam bentuk tertulis (knowledge capture). } \\
\text { b. Meningkatkan kemauan pegawai untuk mempelajari pengetahuan- } \\
\text { pengetahuan terkait TI (learning habit). } \\
\text { c. Meningkatkan kesadaran pegawai untuk mau berbagi pengetahuan } \\
\text { (knowledge sharing). } \\
\text { d. Meningkatkan kesadaran pegawai mengenai peran pengetahuan dan } \\
\text { pemanfaatan kembali pengetahuan (knowledge reuse) dalam menunjang } \\
\text { kegiatan organisasi (knowledge application). }\end{array}$ \\
\hline $\begin{array}{l}\text { Pengetahuan mengenai } \\
\text { proses bisnis internal } \\
\text { maupun yang } \\
\text { berhubungan dengan } \\
\text { eksternal organisasi }\end{array}$ & $\begin{array}{l}\text { a. Koordinasi dengan pihak eksternal untuk mengetahui mekanisme } \\
\text { pertukaran data (knowledge capture). } \\
\text { b. Pembagian pengetahuan kepada pihak-pihak yang terkait } \\
\text { pengembangan e-government (knowledge sharing). } \\
\text { c. Kerjasama dengan pihak internal dan eksternal untuk pemanfaatan } \\
\text { pengetahuan mengenai proses bisnis dalam kegiatan pengembangan e- } \\
\text { government (knowledge application). }\end{array}$ \\
\hline $\begin{array}{l}\text { Pengetahuan mengenai } \\
\text { manfaat/outcomes dan } \\
\text { harapan pengguna dari } \\
\text { sistem informasi (SI) } \\
\text { Pengetahuan mengenai } \\
\text { utilitas sistem informasi } \\
\text { dan umpan balik } \\
\text { pengguna }\end{array}$ & $\begin{array}{l}\text { a.Pendokumentasian manfaat/outcomes yang diperoleh dari aplikasi-aplikasi } \\
\text { yang telah dikembangkan (knowledge capture). } \\
\text { b. Pembagian pengetahuan kepada pihak terkait, salah satunya melalui } \\
\text { presentasi atau melalui Intranet Kemenperin (knowledge sharing). } \\
\text { Evaluasi bersama antara Pusdatin dan pengguna aplikasi untuk mengetahui } \\
\text { utilitas sistem informasi dan memperoleh umpan balik (knowledge capture dan } \\
\text { knowledge sharing). }\end{array}$ \\
\hline $\begin{array}{l}\text { Pengetahuan mengenai } \\
\text { regulasi yang berlaku } \\
\text { Pengetahuan mengenai } \\
\text { reformasi birokrasi }\end{array}$ & $\begin{array}{l}\text { Membagikan pengetahuan agar pengetahuan dapat dimanfaatkan sehingga } \\
\text { memungkinkan proses learning oleh pihak-pihak yang membutuhkan. } \\
\text { Diseminasi informasi tentang reformasi birokrasi melalui portal internal } \\
\text { (knowledge capture dan knowledge sharing). }\end{array}$ \\
\hline $\begin{array}{l}\text { Pengetahuan mengenai } \\
\text { stakeholders } \\
\text { perindustrian, kebutuhan } \\
\text { data/informasinya, serta } \\
\text { ketersediaan } \\
\text { data/informasi di } \\
\text { Kemenperin } \\
\end{array}$ & $\begin{array}{l}\text { Membagikan pengetahuan kepada pihak-pihak yang membutuhkan untuk } \\
\text { meningkatkan kualitas pelayanan informasi industri. }\end{array}$ \\
\hline
\end{tabular}

\subsection{Dukungan Infrastruktur Manajemen Pengetahuan}

Sebagai dukungan terhadap pelaksanaan manajemen pengetahuan, Kemenperin perlu membangun struktur unit pengelola pengetahuan agar pengelolaan pengetahuan menjadi terarah dan memiliki fokus tujuan, meningkatkan kesadaran pegawai mengenai pentingnya dokumentasi pengalaman kerja, memotivasi pegawai Kemenperin untuk berbagi pengetahuan, mengingat inisiatif berbagi pengetahuan masih cenderung rendah, membangun komitmen pimpinan untuk memotivasi pegawai dalam mendokumentasikan pengalaman kerjanya, enerapkan insentif atau reward khusus terhadap inisiatif berbagi pengetahuan yang dilakukan pegawai, menyediakan media berbasis TI bagi pegawai untuk mendokumentasikan pengetahuan, memanfaatkan lebih optimal Intranet Kemenperin sebagai media berbagi pengetahuan, mengingat kemudahan pegawai dalam mengaksesnya, mengelola dan memperkaya pengetahuan umumdalam bidang perindustrian, dan memungkinkan komunikasi berjalan baik dengan memberikan ruangan khusus untuk pegawai berinteraksi dalam suasana formal maupun nonformal. 


\section{Pembahasan}

Penelitian ini bertujuan untuk merumuskan strategi manajemen pengetahuan dalam mendukung reformasi birokrasi Kemenperin. Kemenperin telah memilih peningkatan pelayanan publik sebagai quick wins, yang salah satu proses pendukungnya adalah pengembangan $e$ government. Karena kegiatan pengembangan $e$ government mencakup dukungan terhadap keseluruhan area perubahan reformasi birokrasi, domain ini dipilih sebagai fokus penelitian ini.

Implikasi penelitian ini terhadap organisasi adalah memberikan masukan pada organisasi mengenai strategi pengelolaan pengetahuan yang perlu dilakukan terkait reformasi birokrasi khususnya domain pengembangan e-government. Melalui penelitian ini, organisasi dapat menentukan fokus pengelolaan pengetahuan; yaitu secara garis besar meliputi proses knowledge capture, knowledge sharing, dan knowledge application.

Berdasarkan hasil analisis diketahui bahwa dalam upaya pengelolaan pengetahuan terkait pengembangan e-government, tidak hanya melibatkan unit kerja TI saja, dalam hal ini Pusdatin; namun melibatkan unit-unit kerja lain, serta pihak eksternal Kemenperin yang berkaitan dengan proses bisnis yang didukung oleh $e$ government itu sendiri.

Organisasi juga mendapat masukan mengenai infrastruktur apa saja yang perlu dipersiapkan guna menunjang pelaksanaan manajemen pengetahuan. Infrastruktur manajemen pengetahuan, termasuk di dalamnya infrastruktur TI merupakan faktor pemungkin bagi terlaksananya manajemen pengetahuan sekaligus mendukung strategi manajemen pengetahuan yang telah dirumuskan.

\section{Kesimpulan dan saran}

Sebagai upaya pengelolaan pengetahuan pada domain pengembangan e-government dalam rangka mendukung pelaksanaan reformasi birokrasi Kemenperin, berikut ini adalah rumusan strategi manajemen pengetahuan:

1. Kemenperin perlu melakukan dokumentasi pengalaman-pengalaman kerja ke dalam bentuk tertulis.

2. Kemenperin perlu meningkatkan kesadaran pegawai untuk berbagi pengetahuan.

3. Kemenperin perlu meningkatkan koordinasi dan kerjasama dalam rangka pengelolaan pengetahuan, baik antar unit kerja internal maupun dengan pihak eksternal.

4. Kemenperin perlu memfasilitasi media penyimpanan dan pembagian pengetahuan berbasis TI yang dapat dijangkau dengan mudah oleh seluruh pegawai Kemenperin.

5. Kemenperin perlu membangun komitmen manajemen dalam mendukung pelaksanaan manajemen pengetahuan.

Hal-hal yang disarankan berdasarkan hasil penelitian ini antara lain:

1. Untuk organisasi, disarankan melakukan pengelolaan pengetahuan dalam pengembangan e-government dengan mengacu pada strategi manajemen pengetahuan dan menyediakan infrastruktur manajemen pengetahuan yang dapat mendukung strategi tersebut.

2. Untuk penelitian lanjutan, disarankan untuk melakukan perumusan strategi dalam ruang lingkup domain reformasi birokrasi lainnya.

\section{Referensi}

[1] Becerra, Irma, and Rajiv Sabherwal. Knowledge Management Systems and Processes. New York: M.E. Sharpe, Inc., 2010. Davenport, Thomas H, and Lawrence Prusak. Working knowledge: how organizations manage what they know. Boston, MA: Harvard Business School Press, 1998.

[2] Iskandar, Mario. Perancangan knowledge management system pada perusahaan jasa konsultasi TI studi kasus PT XYZ. Jakarta: Universitas Indonesia, 2009.

[3] Kemenperin. "Capaian Rencana Aksi Reformasi Birokrasi Kementerian Perindustrian Tahun 2013." Jakarta: Pusat Data dan Informasi Kementerian Perindustrian, 2013.

[4] "Dokumen Usulan Reformasi Birokrasi Kementerian Perindustrian." Usulan Reformasi Birokrasi. Jakarta: Kementerian Perindustrian, 2011.

[5] Kementerian PANRB. Peraturan Menteri Negara Pendayagunaan Aparatur Negara dan Reformasi Birokrasi tentang Pedoman Pelaksanaan Program Manajemen Pengetahuan (Knowledge Management). Jakarta: Kementerian Pendayagunaan Aparatur Negara dan Reformasi Birokrasi, 2011.

[6] Matturro, Gerardo, and Andres Silva. "A knowledge-based perspective for preparing the transition to a software product line approach." Proceedings of 9th Software Product Lines International Conference, 2005: 96-101.

[7] Rolano, Maria Gracia Deita. Pembentukan strategi knowledge management untuk 
62 Journal of Information Systems, Volume 10, Issue 1, April 2014

koordinasi penanganan bencana: model koordinasi UN OCHA. Jakarta: Universitas Indonesia, 2008.

[8] Zack, Michael H. "Developing a knowledge strategy." California Management Review, 1999: 125-144.
[9] Zack, Michael H. "Developing a knowledge strategy: epilouge." In The Strategic Management of Intellectual Capital and Organizational Knowledge: A Collection of Readings, by N Bontis and C. W. Choo. Oxford University Press, 2002. 